\title{
May the odds be ever in your favor: The Hunger Games and the fight for a more equal society. (Negative) Media vicarious contact and collective action
}

\author{
Loris Vezzali $^{1 \text { (D) | Shelley McKeown }}{ }^{2}$ ID | Patrick McCauley ${ }^{3}$ | Sofia Stathi ${ }^{4}$ | \\ Gian Antonio Di Bernardo ${ }^{1}$ | Alessia Cadamuro ${ }^{1}$ | Valeria Cozzolino ${ }^{1}$ | Elena Trifiletti ${ }^{5}$ \\ \begin{tabular}{l|l}
1 & INTRODUCTION Abstract
\end{tabular}
}

We fight, we dare, we end our hunger for justice

Katniss Everdeen

Research has shown that reducing prejudice through intergroup contact does not necessarily translate into individuals supporting the measures that work toward achieving a more equal society (McKeown \& Dixon, 2017; Saguy et al., 2017). Indeed, while creating the conditions for positive interactions between groups may improve outgroup attitudes, evidence suggests that this can at the same time lead to lower intentions to act in order to re-establish social justice, ironically group members can "benefit" from negative intergroup contact, which has been shown to foster opposition to equality among advantaged group members (Reimer et al., 2017). In the present research, we aim to test how negative contact can promote advantaged group members' intention to engage in actions in support of the disadvantaged group. This requires alternative methodological approaches; here, we focus on negative media vicarious contact.

Research has shown that vicarious contact, the observation of interactions between ingroup and outgroup members, can reduce prejudice

when observed directly (Dovidio et al, 2011; Vezzalietal, 2014), and when

it occurs via the media, such as books or films (Joyce \& Harwood, 2014; Vezzali et al., 2015). To date, however, the effects of vicarious contact on collective action have been rarely tested (for exceptions, see Bilali \& Vollhardt, 2015; Bilali et al., 2016, 2017, relying on vicarious contact via radio programs), and we are not aware of any study using vicarious contact to promote advantaged group members' collective action on behalf of disadvantaged groups. This is vital because support from advantaged groups is key to achieving social change (see also Becker \& Tausch, 2015).

Addressing a current gap in scientific understanding, the present research examines whether negative vicarious contact via reading the fantasy saga "The Hunger Games" can foster collective action among advantaged group members in support of a disadvantaged group. To investigate the underlying processes and moderating mechanisms to understand for whom reading the books might be most effective in promoting collective action intentions, we examined anger against injustice as a mediator and social dominance orientation (SDO, Sidanius \& Pratto, 1999) as a moderator. We tested our assertions in one correlational study with samples from the United States and United Kingdom and one experimental field study in Italy.

\section{2 | COLLECTIVE ACTION}

Research on collective action mainly focuses on how the members of disadvantaged groups react to their lower-status position. In general, this research suggests that disadvantaged group members' collective action is encouraged by actions that disrupt intergroup relations. One of the main psychological approaches to the study of collective action is the social identity model of collective action (SIMCA) proposed by van Zomeren et al. (2008). This model combines the three psychological tenets of perceived injustice, social identity, and perceived efficacy to collective action, merging them in a unitary framework.

To support the importance of perceived injustice in explaining collective action intentions the SIMCA draws on research on relative deprivation resulting in a stronger hierarchization of society (Saguy et al., 2017). Recognizing this, there is evidence demonstrating that disadvantaged (Runciman, 1966), whereby feelings of deprivation are seen to be a function

of unfavorable social comparisons with the advantaged group. These unfavorable social comparisons imply awareness of intergroup inequalities, and can lead disadvantaged group members to experience feelings of injustice that motivate engagement in collective action (Smith et al., 2012). There is now consistent evidence that anger toward injustice (that we tested as a mediator in the present research) instigates collective action. In particular, it is typically associated with disadvantaged group members' intentions to engage in action to restore social justice (Hayward et al., 2018; Stathi et al., 2019; Tausch et al., 2015; Ufkes et al., 2015).

In addition to perceived injustice, the SIMCA draws on social identity theory (Tajfel \& Turner, 1979) to highlight the importance of social identity, and specifically identification with one's disadvantaged group as an important driver of greater willingness to engage in collective action. Finally, 
the SIMCA model recognizes the need to consider perceptions of collective group efficacy (Bandura, 2000), that is, perceptions that planned actions can be effective in changing the unequal intergroup situation (van Zomeren et al., 2004).

In a revision of the original model, van Zomeren et al. (2012) acknowledged that it is also important to understand the processes through which advantaged group members engage in collective action on the behalf of the disadvantaged group. Specifically, the authors integrated their model by focusing on moral convictions, which refer to "strong and absolute stances on moral issues" (p. 52) and that are activated by perceptions of violations of moral standards. Other authors have recognized the importance of focusing on the advantaged group. The political solidarity model of social change (Subašić et al., 2008), for example, focuses on the conditions under which advantaged groups will support disadvantaged group members. The model places political solidarity at the center, implying an alliance between advantaged and disadvantaged groups in terms of shared political orientation.

In the present study, we focus specifically on anger as an affective mechanism that has been found to be central on mobilizing collective action among disadvantaged groups (Tausch et al., 2015; Ufkes et al., 2015). We aim to provide a novel strategy that facilitates collective action intentions among advantaged group members. Specifically, we examine how the processes that typically motivate disadvantaged group members' collective action (and specifically, anger against injustice) can be re-directed to promote an alliance between disadvantaged and advantaged groups and lead the latter to commit to supporting social equality.

\section{3 | MEDIA VICARIOUS CONTACT}

Vicarious contact can be defined as the observation of interactions between ingroup and outgroup members (Dovidio et al., 2011; Vezzali et al., 2014). When tested in the laboratory it has generally been operationalized as video watching (Mazziotta et al., 2011; Preuß \& Steffens, 2020) and in naturalistic contexts as story reading; that is, short ad hoc created stories where ingroup characters have positive interactions with outgroup characters (Cameron \& Rutland, 2006; Mäkinen et al., 2019; McKeown et al., 2017; but see Vezzali et al., 2019). There is now a large body of evidence showing that observing positive intergroup interactions is associated with reduced prejudice (Mazziotta et al., 2011; West \& Turner, 2014).

In addition to demonstrating the role of positive vicarious contact in reducing prejudice (Vezzali et al., 2014), a smaller body of research has examined negative vicarious contact, that is, observing negative interactions between ingroup and outgroup members. Findings from these studies parallel those of direct contact, showing that negative contact has detrimental effects on intergroup relations that are opposite to the effects of positive contact (Graf \& Paolini, 2017). Specifically, negative, in contrast to positive, vicarious contact has been found to negatively impact on outgroup attitudes (Andrews et al., 2018; Castelli et al., 2012; Joyce \& Harwood, 2014).

Research on vicarious contact partially overlaps with research on media contact, where individuals engage with content shared via the media that depicts interactions between ingroup and outgroup members (and not when it is merely concerned with simple exposure to the outgroup, for instance to outgroup information, experiences, or news; e.g., Visintin et al., 2017; Wojcieszak \& Azrout, 2016). Research on media contact has been mostly concerned with positive vicarious contact, where the observation of positive interactions between media characters has been found to be associated with improved outgroup attitudes (Lienemann \& Stopp, 2013; Mares \& Pan, 2013; Ortiz \& Harwood, 2007; Schiappa et al., 2005; Vezzali et al., 2015). Evidence for negative vicarious intergroup contact via the media is basically nonexistent. One exception is Weisbuch et al. (2009; see also Dovidio, 2009), who found that White viewers observing negative interactions between White people and Black people in television displayed increases in implicit prejudice toward Black people (see also Mastro, 2009, for evidence of effects of exposure to negative portrayals of group members in the media). Note that none of the mentioned studies examined negative vicarious contact via book reading.

There are different theories that can explain the potential effects of vicarious contact. According to vicarious dissonance theory (Cooper \& Hogg, 2007), individuals can resolve the inconsistency between positive attitudes toward the outgroup observed during intergroup interactions and own negative outgroup attitudes by improving their own outgroup attitudes. Relatedly, based on vicarious self-perception theory (Goldstein \& Cialdini, 2007), it can be predicted that instead of inferring own attitudes from the observation of own behavior as posited by self-perception theory (Bem, 1972), individuals infer their outgroup attitudes from the observation of ingroup members positively interacting with outgroup members. Especially relevant for the present study is social cognitive theory (Bandura, 1986), according to which individuals derive information on what to think and on the behavior they should adopt from the observation of ingroup members during interactions with the outgroup.

Vezzali and Stathi (2021) introduced the concept of media vicarious contact, referring to vicarious contact via the media, such as radio, television, and books. Media play a key role in the formation of attitudes toward outgroups (Mutz \& Goldman, 2010). In the present research we focused specifically on book reading. In contrast to "classic" vicarious contact, which relies on observed interactions, media vicarious contact via book reading is characterized by arguably different psychological processes, such as experience-taking (Kaufman \& Libby, 2012) and transportation (Green \& Brock, 2000). Kaufman and Libby (2012) define experience-taking as an "immersive phenomenon of simulating the mindset and persona of a protagonist" (p. 2). With the process of transportation, readers "are absorbed into a narrative world" and as a consequence "may show effects of the story on their real-world beliefs" (Green \& Brock, 2000, p. 701). According to Green and Brock, when readers are transported into a story, they can allocate all their psychological processes on the narrative. At the same time, absorption into a narrative implies strong emotional reactions to events narrated in the story. In the present research, we expected that readers will be absorbed into the story, and (depending on individual ideological differences; see section on "Social dominance orientation") will also be able to connect the fantasy narrative with the real world. In so doing, they are expected to activate in response specific emotions (anger against injustice-see paragraph "The present research"), which in turn should be 
associated to intentions to engage in collective action in support of real-life disadvantaged group members.

This hypothesis is consistent with social cognitive theory (Bandura, 2004) since, being absorbed into the narrative, readers should acquire a mindset and behaviors associated with the main characters (Krause \& Appel, 2020), and translate them in attitudes and behaviors in "real" situations that are in a way comparable to what they have read. In our case, we expect that readers will translate attitudes toward social injustice as read in the books to real-world situations, where they can identify advantaged and disadvantaged groups in a social hierarchy (for instance, where they are the advantaged group at the expense of disadvantaged groups).

Although these processes are theoretically possible when using videos or other types of media channels, we argue that they are more likely when book reading is involved (cf. Green \& Brock, 2000). This is because reading allows introspection of characters, fostering theory of mind and associated constructs like empathy (Kidd \& Castano, 2013; Mar \& Oatley, 2008). Contrastingly, films develop in a much narrower time frame and are more likely to be focused on events rather than introspection (at least compared to a book). For these reasons, we focused on the books of The Hunger Games saga rather than on the films (although we also test the effects of video watching in this research).

Preliminary evidence for the role of books in improving outgroup attitudes has been provided by Vezzali et al. (2012), showing that books which presented stories of characters from distinct cultures interacting positively was associated with more positive intentions to befriend outgroup members. Vezzali et al. (2015) extended these findings to fantasy books, specifically Harry Potter, in three studies. In the first experimental study, Italian elementary school children, in small groups guided by an experimenter, read and discussed in six sessions passages from the Harry Potter saga. Passages were selected to relate to prejudice, highlighting situations where Harry Potter and his friends engaged positively with members from stigmatized fantasy groups. Results revealed that children transferred this positive vicarious contact to real-world situations. Specifically, the authors found that, compared to a control conditions where participants read Harry Potter passages unrelated to prejudice, reading Harry Potter passages related to prejudice was associated with more positive attitudes toward immigrant children among participants who identified more with Harry Potter. These results were confirmed in two subsequent correlational studies conducted with adolescents and adults, where the outgroup was represented by gay people and refugees, respectively, providing evidence for perspective-taking as the underlying process.

Contact research has, however, shown that improving outgroup attitudes does not equate to fostering collective action (Saguy et al., 2017). The role of negative intergroup contact as an instigator of collective action is of particular interest and has recently started to be examined (Meleady \& Vermue, 2019). In the present research, therefore, we focus on examining negative (media) vicarious contact, testing whether it can lead advantaged group members to actively support the disadvantaged group, using both correlational and experimental methodologies. We hypothesize that, through reading The Hunger Games, participants will experience negative contact at the "fantasy" level. In reading the story, they will see the story from the point of view of the disadvantaged group in the book, following the narrative and the protagonists' adventures. This negative contact should form the basis for an alliance with the real-life disadvantaged group with the goal to restore social equality (see The present research). How participants interpret disadvantage, however, may depend on the extent to which they support the existence and maintenance of social hierarchies.

\section{4 | SOCIAL DOMINANCE ORIENTATION}

Social dominance orientation (SDO; Sidanius \& Pratto, 1999) is an individual difference variable tapping on the social ideological level and referring to the desire for unequal relationships among groups. Individuals high in SDO support status inequalities and the dominance of advantaged groups over subordinate disadvantaged groups. SDO is typically associated with prejudice toward a wide range of stigmatized groups, such as ethnic minority groups, gay people, people with disabilities, etc. (Pratto et al., 2006).

Contact research over the past few years has identified SDO as a consistent moderator of contact effects. Although Allport (1954) was skeptical about the potential of intergroup contact to overcome individuals' ideological resistance, studies mainly conducted in the last decade have provided a more optimistic picture, showing that contact is especially beneficial for individuals with higher SDO. In other words, contact works best when individuals are negatively oriented toward the outgroup, that is, when they are more prejudiced (Hodson \& Dhont, 2015; Hodson et al., 2017). Evidence, however, is mixed. Some studies have also found that contact effects were only significant among individuals with lower SDO (Asbrock et al., 2012; Schmid et al., 2012; for absence of moderation effects by SDO, see Kauff et al., 2016; Meadows et al., 2017).

Research examining whether SDO moderates the effects of negative contact is scarce. Dhont and Van Hiel (2009, Study 2) found among advantaged group members that negative contact was more strongly associated with prejudice in high-SDOs. Wang et al. (2020) replicated this effect among advantaged group members, whereas among disadvantaged group members negative contact was associated with greater prejudice among low-SDOs. Meleady and Vermue (2019) conducted two correlational studies testing among advantaged group members whether SDO moderated the effects of both positive and negative contact on collective action intentions. To the best of our knowledge, this is the only study that has tested whether SDO moderated the effects of contact on collective action on the behalf of disadvantaged groups. However, none of the two studies provided evidence for such moderation.

Despite the importance of understanding the ways in which individual differences are associated with contact effects, research examining the moderating role of SDO on the effects of indirect (not face-to-face) contact is limited. The research that has been conducted in this area has produced mixed results. Schmid et al. (2012) found that the effects of extended contact (an indirect contact form conceptually similar to vicarious contact; Vezzali et al., 2014; Wright et al., 1997; Zhou et al., 2019) on outgroup attitudes were stronger for low-SDOs; in this study, however, the measure 
of extended contact was averaged with a measure of direct contact, making the effects of the two indistinguishable. SDO has also been tested as moderator of the effects of imagined contact, an indirect form of contact based on the mental simulation of an interaction with an outgroup member (Crisp \& Turner, 2012; Miles \& Crisp, 2014; Stathi et al., 2012). Findings however revealed a mixed picture, with effects of imagined contact emerging among low-SDOs (Asbrock et al., 2013, Study 1), high-SDOs (Visintin et al., 2019), or unmoderated by SDO (Asbrock et al., 2013, Study 2). No study to date has investigated whether SDO moderates the effects of vicarious contact. We directly assess this by examining whether the relationship between reading The Hunger Games and collective action intentions varies depending on an individual's level of SDO.

\section{5 | THE HUNGER GAMES}

\section{1 | The story}

The Hunger Games is a popular fantasy saga by writer Suzanne Collins consisting of three books (The Hunger Games, Catching Fire, Mockingjay), that have also been adapted into four films. The main character is Katniss Everdeen, a counter-stereotypical 16-year-old woman. Katniss looks after her mother and young sister (her father died in a work accident and her mother is severely depressed), and hunts to feed her family by means of a bow in the forests surrounding the district she lives in. The main male character is Peeta Mellark, a 16-year-old man in love with Katniss, who will fight with and for her along the saga.

The action takes place in a Panem, a post-conflict society where the Capitol (city) is the dominant region that holds the power and whose inhabitants benefit of disproportionate goods and privileges. There are 12 districts that are in a disadvantaged position, whose inhabitants live in extreme poverty and are constantly humiliated by the dominant group. The Hunger Games are a way to humiliate and subdue the disadvantaged groups. They consist of annual "games" where each of the 12 districts has to provide a male and a female tribute between 12 and 18 years old who will fight to death, with only one surviving tribute as the winner. The entire population of districts forcibly has to assist in the games, which are explicitly designed to torture and humiliate tributes, and consequently the districts, emphasizing power dynamics. Inhabitants of the Capitol watch live steams of the games, as if they are a reality show.

Katniss (first book-The Hunger Games) voluntarily takes part in the games, instead of her little sister who was randomly selected to participate; Katniss and Peeta are the tributes for their district (district 12, the poorest). Katniss is strongly focused on her duty to remain alive in order to provide for her family. She finds an unexpected ally in Peeta, who has always been in love with her and is determined to play in order to allow Katniss' final victory, at the expense of his own life. But because of their strong love, to make the games more exciting, the presenter announces that on that year two winners from the same district are allowed. As the games progresses, Katniss and Peeta (playing the part of a couple in love, with Katniss clearly faking it) are the only survivors, at which point the presenter announces that the rules have changed again and only one winner is allowed. Katniss then makes a symbolic gesture, that she and Peeta will commit suicide, leaving the game with no winners, that is seen as an open challenge and a provocation to the power of the Capitol.

Many of the districts interpreted Katniss's gesture as a call for rebellion (second book-Catching Fire). Katniss and Peeta engage in a "victory tour" and experience the presence of underlying repressed rage and "peacekeepers" in the districts they visit. As uprisings begin, Katniss agrees to marry Peeta. Violating the "classic" rules, it is announced that the next Hunger Games will take place with previous winners only. Katniss and Peeta have to take part again in the games, with the explicit task for Katniss to convince the whole population that their gesture in the previous year's games was out of love (their marriage is clearly not enough) rather than a challenge to the power of the Capitol (otherwise she and her family would be killed). The Capitol is afraid of a potential revolution (the Hunger Games were developed as a response to a revolution of many years before). The games end with an escape of most tributes from the arena where they take place, and with many districts in open revolution.

In the final book of the series (third book-Mockingjay), Katniss finds refuge in a 13th district, thought to be destroyed after the first revolution of many years before, but that instead survived and whose inhabitants now live underground. Peeta is a prisoner of the Capitol. Katniss is recruited by the President of District 13 to be the symbol of the revolution. At the end, the Capitol is defeated. Katniss and Peeta (who is released) are deeply exhausted and wear many psychological scars. Nonetheless, they can finally leave in a world where power is equally distributed between districts, and The Hunger Games are a nightmare of the past.

\section{2 | The Hunger Games and the connection with collective action}

The Hunger Games plot has many elements relevant to the literature on vicarious contact and collective action. First, the plot highlights negative vicarious contact: Katniss and Peeta are members of a disadvantaged group, which fights and finds its way by means of a revolution and a war against the advantaged group holding power. The reader can experience this conflict vicariously, by observing through the pages of the book the conflict from the perspective of the disadvantaged group and the main characters of Katniss and Peeta (who, as representatives of the disadvantaged group, repeatedly have extreme negative contact with the advantaged group).

Second, in line with literature on collective action and collective action models such as the SIMCA (van Zomeren et al., 2008), the main factors driving collective action are in place: (a) collective deprivation: the divide between the advantaged and disadvantaged is high and the sense of injustice for the hierarchical divisions is clearly highlighted throughout the story; (b) group efficacy: the books deal with how to make a revolution effective, including many aspects such as symbols, practical means (e.g., armies), visibility (with the media) and a network composed of individuals with different and complementary competences; (c) social identity, exemplified with the belonging to districts where individuals do their best to keep alive (an aspect this reinforced by the writer by enhancing the contrast with the inhumanity of people belonging to the advantaged group), 
and with the attachment shown by characters to people belonging to one's own district. The story also highlights moral concerns (a key factor in the extension of the SIMCA; van Zomeren et al., 2012), that is moral standards that, if violated, can lead advantaged group members to support social change; in this case, the best example of these violated moral standards is represented by The Hunger Games themselves.

\section{6 | THE PRESENT RESEARCH}

We aim to test whether reading the fantasy saga of The Hunger Games is associated with advantaged group members' greater intentions to engage in collective action on the behalf of the disadvantaged group. To examine the underlying and moderating processes we tested anger against injustice as a mediator and SDO (Sidanius \& Pratto, 1999) as a moderator. We tested our assertions in one correlational study with samples from the United States and the United Kingdom and one experimental study in Italy.

Earlier, we discussed research showing that collective action is promoted among disadvantaged group members precisely by factors that disrupt intergroup relations, such as ingroup identification (Stürmer \& Simon, 2004) or perceptions of injustice (Ellemers \& Barreto, 2009). Moreover, we have shown that contact, and specifically vicarious contact, improves intergroup relations when it is positive, and increases intergroup hostilities when it is negative (Vezzali et al., 2014). Wright and Lubensky (2009), in an often-cited chapter, note the incompatibility between contact strategies (that reduce prejudice, but also the conflict necessary for collective action to occur) and factors that promote collective action.

In the present research, we focused on the potential of negative vicarious contact to foster collective action by disrupting intergroup relations, by testing whether it can be instead used to unite advantaged group members with members of disadvantaged groups in the battle against intergroup inequalities. Specifically, we examine among advantaged group members the effects of reading about negative contact between fantasy advantaged and disadvantaged groups from the perspective of the disadvantaged group on collective action intentions to support real-life disadvantaged groups. With negative contact from the disadvantaged alliance with the disadvantaged group to restore social equality. Therefore, we focus on negative contact as a process, without reinforcing negative relations between real groups, instead aiming to create a "moral" alliance between advantaged and disadvantaged groups from the perspective of the advantaged group.

We focused on anger against injustice as the mediating process. Above, we presented research showing that disadvantaged group members' collective action is predicted by anger against injustice. However, there is also evidence that anger against injustice can motivate members of the advantaged group to restore social equality (Hayward et al., 2018; Leach et al., 2006; Selvanathan et al., 2017; see also Thomas et al., 2009). Relevant to the present research, anger against injustice has been further shown to be a reliable predictor of collective action, even among bystanders not directly involved in the issue under examination (Saab et al., 2015). We aim to extend these findings, considering advantaged group members who, while taking the role of bystanders in media vicarious contact (story reading) concerning fantasy groups (from The Hunger Games), convert what they observe into greater awareness of injustice in unequal relationships that they are directly involved in.

SDO is tested as a moderator. SDO is especially relevant when examining collective action, which precisely refers to actions related to unequal relations between groups. For this reason, we expect that inclinations toward sustaining hierarchies can impact on the appraisal of vicarious contact in a (fantasy) context presenting large social disparities.

The proposed theoretical model is presented in Figure 1. Based on the literature reviewed, we predict that vicarious contact via book reading will be associated with greater anger toward injustice and, in turn, greater collective action intentions among individuals higher in SDO. However, because of mixed findings concerning the moderating effects of SDO in direct, and especially indirect contact research, we acknowledge that other moderation patterns may emerge.

Hypotheses were tested in two studies. The first study is correlational, with samples from the United Kingdom and United States. In the second study, which is experimental, we aimed to assess causal relations between book reading and our variables. Specifically, we conducted a 6-month intervention in Italian high-schools to assess this.

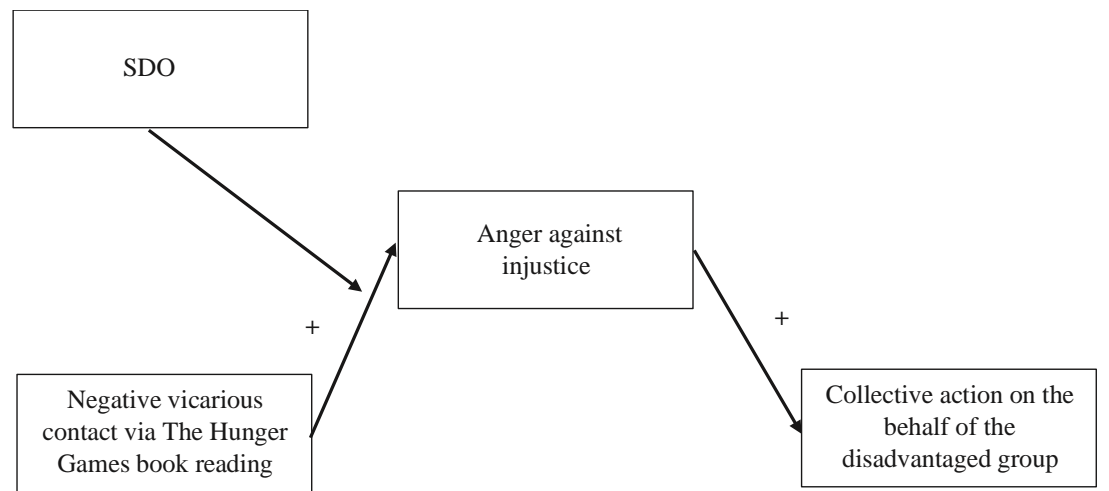

groups' perspective, readers can become aware of inequalities, translating them to real intergroup situations and this, in turn, can foster collective action. In other words, by experiencing negative contact at the "fantasy" level, relations with "real" disadvantaged groups are not disrupted as they would be if negative contact was experienced in real life. In contrast, the awareness created by negative vicarious contact can form the basis for an
FIGURE 1 Proposed theoretical model 


\section{7 | STUDY 1}

\section{1 | Method}

\subsection{1 | Participants and procedure}

The US subsample comprised 128 Caucasian adults living in the United States. We excluded 44 participants for excessive number of missing data or data totally missing on the outcome variables. The final sample consisted of 84 adults ( $79.8 \%$ females) with a mean age of 31.70 years $(S D=15.90)$.

The UK subsample initially comprised 83 White British participants. We excluded five participants for excessive number of missing data or data totally missing on the outcome variables. The final sample consists of 78 adults ( $79.5 \%$ females) with a mean age of 25.38 years $(S D=8.61)$.

Because of the rather low sample sizes (i.e., both samples were underpowered since they were less than 155 , the minimum size for a multiple regression with up to four predictors, power $=.80$, small to medium effect size $=.08$ ), and since the hypotheses and questionnaire for the two samples were identical, data were merged resulting in a final sample of 162 participants ( $79.6 \%$ females), with a mean age of 28.66 years $(S D=13.26) .{ }^{1}$ The disadvantaged group was African Americans for the US subsample and refugees for the UKsubsample.

Participants were distributed an online questionnaire via email invitation, social media and through a university participation pool

TABLE 1 Means, standard deviations, and correlations among variables (Study

$1, N=162$ book of the saga as a single film. This way the measure for films and books was comparable).

\subsection{2 | Social dominance orientation}

To assess SDO the $\mathrm{SDO}_{6}$ scale composed of 16 items (Pratto et al., 1994) was used. Example of one item is: "Some groups of people are simply inferior to other groups." The response scale ranged from 1 (completely disagree) to 7 (completely agree). Items were combined in a reliable index $(\alpha=.91)$, with higher scores reflecting greater SDO.

\subsection{3 | Anger against inequalities}

We used 10 items adapted from general literature on collective action, asking participants how they felt on a range of emotions (e.g., angry and furious) when thinking about the advantaged position of Caucasians relative to African Americans in the United States (US subsample) or of British people toward refugees in the United Kingdom (UK subsample) (e.g., Reimer et al., 2017; Ufkes et al., 2015; van Zomeren et al., 2012). The response scale was anchored to 1 (not at all) and 7 (very much). Items were collapsed in a reliable index $(\alpha=.88)$, with higher scores denoting more anger about the unfair position of the disadvantaged outgroup.

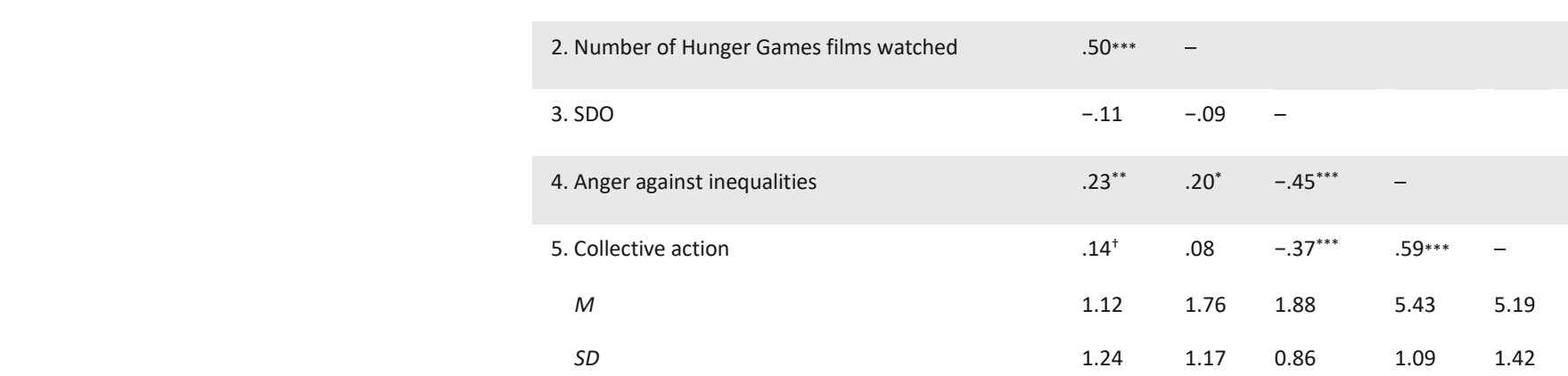

Note: The response scale ranged from 1 to 7 for all measures, with the exception of number of Hunger Games books read and films watched (scale $0-3$ ).

$+p<.10 ;{ }^{*} p<.05 ;{ }^{* *} p<.01 ;{ }^{* * *} p<.001$.

directed at university students in the United Kingdom and the United States.

\subsubsection{Collective action}

\section{2 | Measures}

\subsection{1 | The Hunger Games books read and films watched}

Participants were asked to indicate the books read (from 0 to 3 ) and films watched (from 0 to 3 , considering the two last films concerning the final
We assessed intentions to engage in collective action by means of four items adapted from those commonly used in collective action research, concerning intentions to participate in various actions (e.g., signing a petition and taking part in a demonstration) aimed at improving the position of the disadvantaged group (e.g., Çakal et al., 2011; Reimer et al., 2017; Selvanathan et al., 2017; van Zomeren et al., 2008). The response scale ranged from 1 (not at all) to 7 (very much). We averaged items in a reliable

\footnotetext{
${ }^{1}$ We compared the UK and US samples on our measures and found differences in two variables: (1) number of films watched, which was higher in the United Kingdom $(M=2.28, S D=1.14)$ than in the United States $(M=1.27, S D=0.99), t=6.04, p<.001$ and, (2) collective action, which was
}

higher in the United States $(M=5.45, S D=1.27)$ than in the United Kingdom $(M=4.91, S D=$ 1.53), $t=2.42, p<.05$. Additional analyses revealed that none of the effects emerged was moderated by sample (United Kingdom vs. United States). 
index of intentions to engage in collective action on the behalf of the disadvantaged group $(\alpha=.88)$.

\section{3 | Results}

Means, standard deviations, and correlations are presented in Table 1. To test our hypotheses, we used the PROCESS macro (Hayes, 2013, Model 7). In the first model testing effects on the hypothesized mediator, we regressed anger against inequalities (mediator) onto (centered) number of Hunger Games books read, SDO and the two-way interaction. The number of Hunger Games films watched was included as a covariate. Results are presented in Table 2. As can be seen, the expected two-way interaction was significant. Decomposition of the interaction revealed that the number of Hunger Games books read was associated with higher levels of anger against inequalities among individuals low in SDO, $b=.24, t=2.62, p<.01$; when SDO was high, the association between number of Hunger Games books read and anger against inequalities was non-significant, $b=-.02, t=$ $.25, p=.804$. (Figure 2).

In the second model (Table 2), we regressed our dependent variable (collective action) onto number of Hunger Games books read and anger against inequalities, again controlling for number of Hunger Games films watched. Results revealed that anger against inequalities was positively associated with collective action, over and above the effects of the other predictors.

Indirect effects tested with bootstrapping procedures (2,000 resamples) revealed that the number of Hunger Games books read was indirectly associated with greater collective action via increased anger TABLE 2 Hierarchical regressions testing the impact of Number of Hunger Games books read via anger against injustice as moderated by SDO on dependent variables (Study $1, N=162$ )

\begin{tabular}{|lll|}
\hline & $\begin{array}{l}\text { Anger against } \\
\text { inequalities }\end{array}$ & $\begin{array}{l}\text { Collective } \\
\text { action }\end{array}$ \\
\hline $\begin{array}{l}\text { Number of Hunger Games books } \\
\text { read }\end{array}$ & $.11(.07)$ & $.03(.08)$ \\
\hline SDO & $-.57^{* * *}(.09)$ & $/$ \\
\hline $\begin{array}{l}\text { Number of Hunger Games films } \\
\text { watched }\end{array}$ & $.08(.07)$ & $-.06(.09)$ \\
\hline $\begin{array}{l}\text { Number of Hunger Games } \\
\text { Books read } \times \text { SDO }\end{array}$ & $-.15^{*}(.08)$ & $/$ \\
\hline Anger against inequalities & $/$ & $.78^{* * *}(.09)$ \\
\hline$F$ & $13.68^{* * *}$ & $28.90^{* * *}$ \\
\hline$R^{2}\left(f^{2}\right)$ & $.26(.35)$ & $.35(.53)$ \\
\hline
\end{tabular}

Note: Non-standardized regression coefficients are reported; standard errors are shown in parentheses.

\footnotetext{
${ }^{2}$ Although not an aim of the present article, we also tested whether SDO moderated the effect of the number of The Hunger Games films watched. We ran a series of regression models identical to those presented in the text. In this case, however, the number of The Hunger Games films watched served as predictor, and number of Hunger Games books read was entered as a covariate. However, none of the effects or the interaction involving number of Hunger Games films watched was significant.
}

${ }^{*} p<.05 ;{ }^{* *} p<.01 ;{ }^{* * *} p<.001$

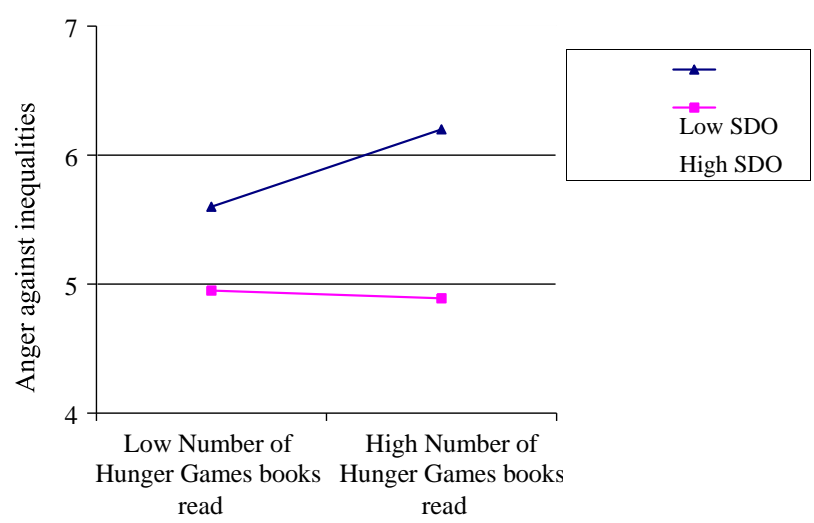

FIGURE 2 Anger against inequalities (response scale 1-7) as a function of Number of The Hunger Games books read and of SDO (Study 1, N=162) [Color figure can be viewed at wileyonlinelibrary. com]

against injustice when SDO was low (effect $=.19, S E=.08,95 \% \mathrm{Cl}[.051$, $.363]$ ), but not when SDO was high (effect $=-.02, \mathrm{SE}=.07,95 \% \mathrm{Cl}[-.236$, .139]). Moreover, the moderated mediation index was significant (effect $=$ $-.12, S E=.06,95 \% \mathrm{Cl}[-.236,-.011])$, . $^{2,34}$

Results provided partial support for our hypotheses. In particular, reading The Hunger Games was associated with greater collective action via increased anger against injustice. This effect was moderated by SDO, such that the indirect effect was significant for low-SDOs (but not high-SDOs, as we had predicted). We conducted a second, experimental study to: (a) obtain causal evidence for the effects of book reading in a field intervention, (b) replicate findings obtained in Study 1, and (c) shed light on the direction of moderation by SDO.

\section{STUDY 2}

\section{$8.1 \mid$ Method}

\subsection{1 | Participants}

In determining the sample size for this study we conducted an a priori power analysis using effect sizes emerged from the previous study. Specifically, in order to achieve a large effect size ( $\geq .35$, see Table 2$)$ allowing a power of .80 (with $p \leq .001$ ) for a multiple regression with up to four predictors, the sample size detected was 76 .

The initial sample comprised 122 Italian high-school students from 10 classes in two high-schools located in northern Italy. The target group was

\footnotetext{
${ }^{3}$ The pattern of findings did not change when controlling for contact (one item asking for the extent of contact with the disadvantaged group), age, and gender.

${ }^{4}$ We conducted additional analyses to test whether subsample (United Kingdom vs. United States) moderated some of the effects found. Results revealed that none of the interactions of subsample involving the number of Hunger Games books read was significant. Therefore, the main findings were not moderated by the subsample.
} 
represented by immigrants. We excluded seven participants from the experimental group who declared they had not read any of The Hunger Games books over the school year (therefore, who did not comply with the task assigned; see Procedure), and 26 participants from the control group who declared that they had neither read any books nor watched any of The Hunger Games films. ${ }^{5}$ The final sample consisted of 89 high-school students (38.2\% women) with a mean age of 15.60 years $(S D=1.56)$. Participants were randomly assigned to the experimental $(N=50)$ or the control condition $(N=39)$. For organizational reason, allocation to conditions was at the level of the class rather than at the level of individuals.

\subsection{2 | Procedure}

The researchers who conducted the intervention were students enrolled in educational academic courses at a northern Italian university and were trained by the first author of the article.

In the experimental condition, researchers met with each participating class, explaining with the assistance of school teachers that participants should read the books of the Hunger Games saga across the school year as part of their school curriculum. They would also have periodical 1-hr meetings with researchers to discuss key passages from the books, once a month for 6 months. Specifically, students were asked to read half a book each month, before the planned meeting where they would read selected passages and discuss them collectively. In total, there were six meetings, each of which aimed to discuss the contents of one half of one of the three books.

Passages were carefully selected for being related to collective action and favoring introspection of main characters and their perceptions and behaviors. We highlighted disparities in resources allocated to advantaged and disadvantaged groups, the unfairness and cruelty of measures adopted by the advantaged group to maintain power, negative emotions experienced by main characters toward the advantaged group, disadvantaged group members' dissatisfaction, impossibility to improve the situation as individuals, strength of Katniss' personality and her orientation toward the unfair system, the importance of symbols for a revolution to occur, its feasibility and conditions allowing it, the inevitability of revolution from the perspective of characters, the development of the revolution, the importance of several components for social change to occur including the role of the media and the leaders to unite people, what is and what is not ${ }^{6}$ We provide two examples of interventions sessions. In the first intervention session, we selected passages highlighting disparities in resources allocated to the advantaged and disadvantaged groups (Katniss forced to hunt to provide her family with food, even if this is forbidden, and how this determines her encounters with soldiers from Capitol city; Katniss arriving in the magnificent Capitol and meeting its inhabitants; Katniss observing the Capitol citizens wealth when the Districts do not even have food and interacting with some of them); the unfairness and cruelty of measures adopted by the advantaged group to maintain power (the description of The Hunger Games as a consequence of negative intergroup relations in the past leading to a war, their unfairness and the way they are designed to humiliate the Districts, such as when participants are selected by Capitol

\footnotetext{
${ }^{5}$ Many participants of the original sample in the control group $(N=39)$ knew The Hunger Games saga because they had read books or watched films, whereas a smaller part of participants $(N=26)$ declared that they had neither read any books nor watched any films. To the extent that we were interested in evaluating the effect of an intervention specifically focusing on highlighting topics connected with collective action, we decided to exclude participants who were not familiar with the saga. In fact, this subsample would have been hardly comparable with the experimental sample, not allowing to distinguish the effects of knowing the saga from that of taking
}

morally allowed in a revolution. In other words, we drew attention to aspects highlighted by collective action research, such as: collective deprivation and awareness of inequalities; illegitimacy, instability and impermeability of status relations; collective efficacy. Most of these passages included negative interactions between advantaged and disadvantaged group members, where power differences were more salient, and which instigated reactions and awareness by members of the disadvantaged group. ${ }^{6}$

In each session, participants were invited in turn to read and discuss selected passages considering their relevance to the real world. The discussions were coordinated by the researchers. Specifically, participants commented on whether inequalities emerged in the books were reflected (although in a less extreme way) in the society where they lived, their consequences and potential actions to achieve an equal society. Attention was placed to stimulate a collective discussion, encouraging participants to provide comments.

Participants were asked to fill an online questionnaire after the end of the last session. Participants in the control condition were simply asked to fill in the questionnaire at the end of the 6 months when also participants from the experimental group were invited to fill in the questionnaire, without taking part in any intervention.

Finally, participants were thanked and fully debriefed.

\section{$8.2 \mid$ Measures}

Measures were the same as those used in Study 1, with the difference that for all measures (except those concerning Hunger Games number of books read and films watched) the response scale ranged from 1 to 5 and the disadvantaged group was immigrants. The measures were confirmed as age-appropriate based on our previous research and consultation with school teachers. Items were combined in reliable indices of SDO $(\alpha=.84)$, anger against inequalities between Italians and immigrants $(\alpha=.83)$, collective action on the behalf of immigrants $(\alpha=.89)$. As control variables, we assessed the number of the Hunger Games books read and films watched (in the latter case counting the last two films concerning the third book of the saga as one film only, in line with Study 1), in order to assess who was familiar with the saga in the control group, and to check who had

city members or have to meet with the inhabitants of Capitol city); negative emotions experienced by the main characters toward the advantaged group (the hatred felt by Katniss in response to injustice and how this affects relationships with the advantaged group); the impossibility of improving the situation as individuals (Katniss discussing with her friend the unlikely escape with their family in the forest to avoid any further contact with soldiers from the Capitol and the imposed limitations); the strength of Katniss' personality and her orientation toward the unfair system (Katniss taking charge of her family after her father's death and as a consequence of her mother's weakness, the way Katniss protects her little sister, the negative interactions of Katnis with individuals appointed to manage them when training for entering The Hunger Games, leading

part into an intervention aimed at highlighting specific issues of it (note that this subsample would also have been too low to conduct reliable statistical analyses). This way, we obtained a control group comparable to the experimental group. In fact, both groups were familiar with the saga, allowing us to test the specific effects of being involved in a reading intervention where the topic of collective action was highlighted and discussed. This represents a more stringent test of our hypothesis, since it considers a control group which is familiar with the saga that we expected to affect collective action intentions. 
her to challenge them). In the third intervention session, we selected passages referring to the cruelty of the dominant group (Katniss is forced to tour the other districts, including those of some of her victims during the Hunger Games, under strict surveillance of individuals from Capitol city that treat her, her friend Peeta, and people from the districts very badly; while attending a party with people from the Capitol, Katniss and Peeta can appreciate the contrast between the opulence of the advantaged group and the suffering

read books as per instructions in the experimental group. ${ }^{6}$

\section{3 | Results}

Means, standard deviations, and correlations are presented in Table 3. To test our hypothesis, we used the same approach as in Study 1. Specifically, we tested our moderated mediation model using the PROCESS macro (Hayes, 2013, Model 7). In the first model, we tested the effect of experimental condition, (centered) SDO, and their product on anger against inequalities. The number of Hunger Games films watched was controlled for. Results are presented in Table 4. As can be seen, the anticipated twoway interaction was significant. Decomposition of the interaction revealed that condition predicted greater anger against inequalities when SDO was high, $b=.43, t=2.33, p<.05$. In contrast, the relation between condition and anger against inequalities was non-significant when SDO was low, $b=$ $-.21, t=1.15, p=.252$ (Figure 3 ).

TABLE 3 Means, standard deviations, and correlations among variables ff the disadvantaged group); the threat representec

$\begin{array}{lll}\text { Condition }(1=\text { Vicarious contact, } & .11(.12) & .06(.20) \\ 0=\text { Control }) & -.60^{* * *}(.11) & / \\ \text { SDO } & .51^{*}(.22) & / \\ \begin{array}{l}\text { Number of Hunger Games Books read } \\ \times \text { SDO }\end{array} & / & .68^{* * *}(.16) \\ \begin{array}{l}\text { Anger against inequalities } \\ \text { Number of Hunger Games films } \\ \text { watched }\end{array} & .10^{+}(.06) & -.09(.10) \\ F & 9.07^{* * *} & 6.25^{* * *} \\ R^{2}\left(f^{2}\right) & .30(.42) & .18(.22)\end{array}$

Note: Non-standardized regression coefficients are reported; standard errors are shown in parentheses.

$+p<.10 ; * p<.05 ; * * p<.01 ; * * * p<.001$.

In the second model, we regressed collective action on condition and anger against inequalities; we controlled for number of Hunger Games films watched (Table 4). As can be seen, anger against inequalities was positively associated with collective action, over and above the other predictors.

Indirect effects tested with bootstrapping procedures $(2,000$ ntention); the beginning of the revolution (people from the Districts starting rebelling and soldiers from the Capitol repressing it with the violence).

(Study $2, N=89$ )

$\begin{array}{lllll} & \mathbf{1} & \mathbf{2} & \mathbf{3} & \mathbf{4} \\ \begin{array}{l}\text { 1. Condition }(1=\text { Vicarious contact, } \\ 0=\text { Control) }\end{array} & - & & & \\ \text { 2. SDO } & & & & \\ \text { 3. Anger against inequalities } & .01 & - & & \\ \text { 4. Collective action } & .10 & -.47^{* * *} & - & - \\ M & .06 & -.52^{* * *} & .42^{* * *} & - \\ \text { SD } & / & 2.50 & 2.87 & 2.86 \\ & / & 0.63 & 0.66 & 1.03\end{array}$

Note: Except for condition represented by a dummy variable, the response scale for all measures ranged from 1 to 5 .

${ }^{*} p<.05 ; * * p<.01 ; * * * p<.001$.

TABLE 4 Hierarchical regressions testing the impact of Condition on collective action via anger against injustice as moderated by SDO (Study 2, $N=89$ )

$\begin{array}{ll}\begin{array}{l}\text { Anger against } \\ \text { inequalities }\end{array} & \begin{array}{l}\text { Collective } \\ \text { action }\end{array}\end{array}$

${ }^{6}$ The questionnaires in both Studies 1 and 2 incorporated additional measures as a part of a wider project on intergroup contact and collective action. All measures included can be found in the online Supporting Information. resamples) revealed that vicarious contact (i.e., the experimental condition) was indirectly associated with higher collective action via greater anger against injustice when SDO was high (effect $=.29, S E=.13,95 \% \mathrm{Cl}$ $[.070, .605])$, but not when SDO was low (effect $=-.14, S E=.14,95 \% \mathrm{C}$ $[-.461, .092])$. Moreover, the moderated mediation index was significant $($ effect $=.34, S E=.16,95 \% \mathrm{Cl}[.065, .470]){ }^{7}$

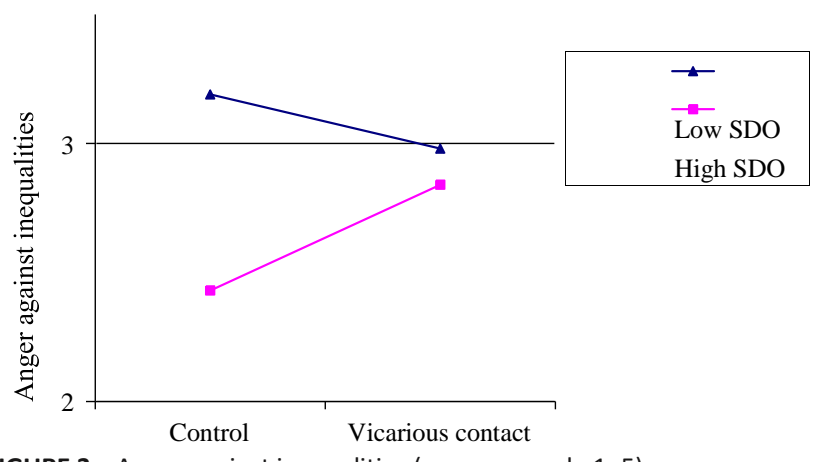

FIGURE 3 Anger against inequalities (response scale 1-5) as a

function of Condition ( $1=$ Vicarious contact, $0=$ Control) and of SDO (Study 2, $N=89$ ) [Color figure can be viewed at wileyonlinelibrary.com]

\footnotetext{
${ }^{7}$ The pattern of findings did not change when controlling for contact (same item used in Study 1), age, and gender.
} 
9

The present research departs from most previous studies on intergroup contact and collective action. To date, studies have generally assessed the effects of positive contact and the conditions allowing positive contact to foster collective action, among both disadvantaged (Saguy et al., 2017) and advantaged groups (Di Bernardo et al., 2019). A small number of studies has tested negative contact as a predictor of collective action, finding that it is associated with greater collective action among the disadvantaged group, but with lower collective action among the advantaged group (Reimer et al., 2017, Study 1b). Clearly, negative contact can disrupt intergroup relations and foster a desired change toward social equality among disadvantaged group members. This is, however, at the expense of peaceful relations between groups, creating barriers to supporting social change among advantaged group members.

It is worth noting that collective action research is largely based on the conditions that promote conflict between groups and lead the disadvantaged group to act for social equality (Wright \& Lubensky, 2009). In the present research, we aimed to use the "destructive" power of negative contact for promoting collective action, by relying on media vicarious contact via book reading. By focusing on a fantasy saga, advantaged group members could identify with a fantasy disadvantaged group and link it to real groups in the society. This way, they were in a better position to recognize social inequality, the immorality of this and the need to act to restore social equality. Our results demonstrate the flexibility of vicarious contact as a tool, both at a practical and at a theoretical level, by showing that negative (vicarious) contact in some conditions can be used to unite groups to the common aim of creating a more equal society.

Specifically, findings revealed that negative vicarious contact concerning fantasy books was effective in promoting collective action intentions on behalf of disadvantaged groups among advantaged group members. Importantly, as anticipated, the effect of vicarious contact was dependent upon SDO. However, the direction of the moderation was inconsistent between the two studies.

While in Study 1 vicarious contact via book reading was associated with greater anger against injustice and in turn stronger collective action intentions among low-SDOs, in Study 2 the indirect effect of vicarious contact emerged only among high-SDOs. These results reflect mixed findings observed in the literature, especially when it comes to indirect contact. Also, note that these are the first studies to test moderation by SDO on vicarious contact (and specifically, negative vicarious contact). Furthermore, this study departs from previous research on vicarious (and more generally direct and indirect) contact, as it specifically aimed to examine whether negative (vicarious) contact has positive effects on outgroup attitudes, in this case, intentions to take part in collective action to restore social equality.

One potential explanation for the diverging patterns of moderation between the two studies concerns the differential appraisal of vicarious contact by readers. In the first study readers were not guided in reading the narrative, and specifically they were not led to focus their attention on how the unjust hierarchical social structure depicted in the books was reflected (albeit surely less dramatically) in society nowadays. In this case, due to their resistances to accept social equality, individuals higher in SDO may have taken the books as a "simple" story, without reflecting on their deeper, generalizable social implications. Books are in fact complex narratives that may bring several messages, and readers are free to explore and interpret these messages also depending on their personal inclinations. In contrast, individuals low in SDO, who are by definition more inclined toward social equality, may have been more attracted by the messages of the books, elaborating on these messages more thoroughly and translating them to real-world situations.

We argue that the intervention realized in Study 2 may have changed the appraisal of the narrative. The intervention was specifically designed to follow readers in their "travel" across the books, focusing on several aspects linked to collective action, as identified by collective action models like SIMCA (van Zomeren et al., 2008, 2012): social deprivation and recognition of injustice, violations of moral standards, and collective efficacy. The intervention also explicitly addressed the link between events in the book narrative and real-world situations: participants were invited to reflect and collectively comment on whether and how the story related to real intergroup relationships, such as between Italians and immigrants in Italy (although the inequality portrayed in the books is extreme compared to intergroup relationships involving participants). This way, individuals with high-SDO (but also low-SDOs) were actively invited to focus on aspects of the story related to the topic under investigation and its potential link with reality. In other words, they were "helped" in overcoming their eventual resistance in addressing intergroup inequalities due to their personal ideological inclinations. It could be argued, therefore, that the observed effects in the present research are the result of a combination between books read and the intervention (including group discussions). Effects may also have been facilitated by the sample used; adults in Study 1 and adolescents in Study 2. Adolescence is a special developmental period leading to greater self-consciousness (Steinberg, 2005) and engagement in novel targets and views to adapt to changing social contexts (Crone \& Dahl, 2012; Hauser et al., 2015). Therefore, it is possible that the intervention favored a reconsideration of own attitudes and intentions among individuals with high-SDO, as a function of interactions with peers during intervention sessions focused on the injustice and consequences of social inequalities.

Contact research shows that high-SDOs can indeed be those that benefit the most from intergroup contact (Hodson et al., 2017). However, this is possible, we add, when they can broaden their attentional focus and recognize social injustices. This can be especially difficult when reading complex narratives that bring on several distinct messages, unless they are guided in this path. This interpretation is consistent with the transportation imagery model (Green \& Brock, 2002), arguing for the importance of evoking transportation and vivid mental images when immersed into the narrative. In particular, in Study 2 the intervention may have enhanced salience and importance of the books in the readers' eyes, tangentially fostering transportation among those less initially inclined to pay attention to it (and its message) because of personal dispositions (highSDO). In Study 1 , in absence of the "help" provided by an intervention, transportation and 
vivid mental images have been likely to be active only among those more ideologically predisposed to elaborate the book message (lowSDO).

This explanation is supported by the decomposition of interactions in our two studies. In Study 1 (Figure 2), individuals with high-SDO did not differ from low-SDOs when the number of the books read was low. In this case, low-SDOs benefitted from reading, demonstrating an increase of intentions to engage in collective action that allowed a differentiation from high-SDOs. As we argued, reading possibly captured the attention of individuals with a less pronounced ideological resistance and more inclined toward social equality (one of the main messages of the books), that is lowSDOs; but book reading did not benefit high-SDOs, who may be insufficiently motivated to focus on the message of the book, elaborate it and transfer it to real-world situations. In Study 2 (Figure 3), in the control condition low-SDOs differed from high-SDOs, such that low-SDOs displayed greater anger against injustice. The intervention however was likely to overcome the ideological resistance of highSDOs, who as a consequence of the intervention displayed similar levels of anger against injustice as lowSDOs. The intervention may have been less effective for low-SDOs because in this case they had relatively high levels of the outcome variable already from the onset of the study.

The present research can help shed some light on the moderating role of SDO on intergroup contact. The literature reviewed showed that although SDO often interacts with contact, the direction of effects can differ, with contact effects sometimes larger for low-SDOs and other times larger for high-SDOs. Such inconsistency is much higher for indirect contact studies, where tests of moderation are much scarcer. Our study exemplifies this inconsistency, with two vicarious contact studies based on the reading of the same books that provided contradictory patterns of findings. In line with a person $\times$ situation approach (Hodson \& Dhont, 2015), we believe person level variables are important to understand when contact is more likely to display effects. Based on the present findings, we further argue that, at least for indirect (vicarious) contact, context is an additional variable that cannot be neglected. The question in fact is not whether contact effects can depend on SDO; there is already ample evidence for this. What is less clear is when each pattern is likely to emerge, that is when contact effects will be strengthened (or lowered) by low or high levels of SDO. Our research represents a step in this direction, showing that vicarious contact can benefit high-SDOs when they are in the position to change their focus by overcoming their resistance against change, for instance with an intervention like the one we presented.

A further relevant finding concerns anger against injustice as the underlying process explaining higher intentions to support collective action to benefit the disadvantaged group. The present two studies provided converging evidence that vicarious contact can highlight perceptions of injustice and associated anger against it, which in turn is a strong predictor of collective action. This result is in line with collective action research, showing that perceptions of injustice and the emotional reactions they stimulate are key to bring individuals to personally engage in actions for social change (van Zomeren et al., 2008), also when these actions are performed by members of the advantaged group (e.g., Hayward et al., 2018; Selvanathan et al., 2017).
Although we tested anger against injustice as a mediator, there are several other potential mediating variables. Among these, perceptions of collective efficacy, social identity, and moral convictions, which are key elements of the SIMCA (van Zomeren et al., 2008, 2012). In particular, we believe ingroup identification is an especially relevant mediator. First, it is an established predictor of intergroup bias and collective action (Adra et al., 2019; Çakal et al., 2011; Stathi et al., 2019; Thomas et al., 2012; Thomas et al., 2020; see also van Zomeren et al., 2008). Second, a reduction in ingroup identification may be related to the concept of deprovincialization proposed by Pettigrew (2009), whereby individuals realize that ingroup customs, traditions, and social norms are not the only way to manage and interpret social reality. This deprovincialization process should allow greater openness toward the outgroup and as a consequence more positive outgroup attitudes (Verkuyten et al., 2010). It is important to note, however, that not all types of identification predict intergroup bias. For example, secure identification is unlikely to motivate ingroup bias (Tajfel \& Turner, 1979) and have detrimental effects on collective action. Evidence for this comes from Górska et al. (2020), who found that it was the collective narcissistic side of ingroup identification rather than secure identification that motivated reduction in solidarity-based collective action. Future research should investigate collective narcissism and its association with vicarious contact and collective action more closely.

Although this research was not designed to test the effects of film watching, nonetheless we examined it with exploratory purposes. No effects emerged in Study 1, neither direct nor moderated by SDO (Footnote 1). Also Study 2 did not provide evidence of effects of films watched, neither on anger against injustice nor on collective action intentions. It is possible that The Hunger Games films do not allow the same degree of introspection or analysis of the situation as the books, and their potential for the activation of processes like transportation (Green \& Brock, 2000) is lower (cf. Vezzali et al., 2015). However, films have some practical advantages in terms of using as an intervention: they can be shown collectively and do not require significant time commitments from the participants' perspective, making them more time efficient. Future studies may focus on films specifically, and examine how interventions can allow vicarious contact via film watching to promote collective action.

It is important to note that the story underlying The Hunger Games saga is deeply concerned with the theme of injustice from the perspective of the disadvantaged group, leading the reader to become aware of unfairness and injustice in the social hierarchy. In other words, the books are not merely concerned with negative vicarious contact. As a consequence, it is likely that our findings do not merely reflect negative vicarious contact, but also the broader theme of injustice that is shown in the books. We believe this is an unavoidable consequence of the choice to use a real book saga as stimulus. Books are in fact complex tools, from where readers can extract many messages and where messages can be presented in different ways. It is important to highlight, however, that negative interactions between characters are central to the storyline and are used to exemplify injustice between groups, making it likely to affectively move the reader, bolstering feelings of anger against injustice as an emotional reaction. Future research should take these observations into consideration, and try to disentangle 
how the different ways a message is presented in books can differentially affect attitudes.

In the present research, we did not explicitly test social identity, efficacy, or moral convictions. Nevertheless, the SIMCA offers an important theoretical perspective that guided our choice to focus on the Hunger Games saga, and motivated the use of anger toward injustice as the process linking negative vicarious contact with support for collective action. Future research can test a more complete account of the SIMCA in the context of vicarious contact.

The present research also offers some support for Subašić et al. (2008)'s political solidarity model of social change, focusing on the advantaged group. The authors argue that groups can adopt a dual identity, maintaining their original identity, but also adopting a shared superordinate identity that makes intergroup solidarity possible (see also Gaertner \& Dovidio, 2000; Simon \& Klandermans, 2001). Our study is consistent with Subašić et al.'s model, since reading the books should have encouraged participants to recognize inequalities in the relationships of the advantaged group with the disadvantaged group. Such recognition theoretically would have fostered anger against injustice and potentially led to the adoption of a superordinate identity characterized by strong moral standards (see also Vezzali \& Stathi, 2021), which in turn, motivated collective action. Future studies should examine these underlying processes more precisely, focusing in particular on whether advantaged and disadvantaged group members adopt a shared categorization beyond their group identities, the defining characteristics of this superordinate identity, and whether it is predictive of collective action.

The present research adds to the growing literature showing the impact of literature on outgroup attitudes and social change (Pennington \& Waxler, 2017), and more generally on a wide range of positive outcomes (Oatley, 2016; Shaffer et al., 2018). We believe this study also contributes to advancing literature on vicarious contact. In addition to being the first set of studies to test whether vicarious contact effects are moderated by SDO, we are not aware of other indirect contact studies specifically aimed to foster collective action among advantaged group members. A further contribution of this research is that we used negative vicarious contact to produce beneficial effects aimed at fostering a more equal society. Relatedly, in line with models arguing for political solidarity (Simon \& Klandermans, 2001; Subašić et al., 2008), the present research goes in the direction of achieving social change by actively involving members of the advantaged group, when in fact most collective action research focused on stimulating action by the disadvantaged group members (see also Di Bernardo et al., 2019; Hasan-Aslih et al., 2019; Vezzali et al., 2017). Whereas Wright and Lubensky (2009) argued for the incompatibility between contact and collective action research for fostering collective action, we believe researchers should find ways to combine the beneficial effects of contact (reduction in intergroup hostility) with the effects of factors identified as precursors of collective action (such as recognition of injustice and violation of moral standards). In this study, we relied on the destructive power of negative vicarious contact, which we used to unite groups against unfair inequalities in the real world. Note that we used a special type of (media) vicarious contact, where readers identify with a fantasy group rather than with an existing ingroup (cf. Vezzali et al., 2015). We argue that what is important is not whether the ingroup is "real" or not, but whether the narrative allows the reader to see the story as a member of an ingroup interacting with an outgroup, in order to stimulate psychological processes underlying the effects of intergroup contact.

The present findings have important practical implications. They suggest that book reading is a viable and effective way to promote a culture of social equality. Books do not necessarily need to be about real-world situations, which might eventually raise threat and resistance about acknowledging social disparities among readers. They can instead be fantasy books, allowing for elaboration and translation of the message to realistic contexts. Importantly, low- and highSDOs may respond differently to reading, therefore it is especially important to increase the focus on social inequalities shown in the books and guiding the readers in reflecting about their relevance and applicability to naturalistic situations. Books can be eventually designed to help readers capture their message, with specific exercises or explicit focus.

We acknowledge some limitations of the present research. First, in Study 2, the longitudinal nature of the intervention, which protracted over 6 months, does not allow us to exclude additional unregistered events that may have affected results. Second, in Study 2 because of practical constraints we did not assess SDO before the intervention, as would be methodologically correct for moderators. Note however that condition and SDO were not correlated (Table 3), therefore, supporting the role of SDO as a moderator to be tested. Third, we postulated that individuals have translated social injustice as read in the books to social injustice that exists in real-world society. In Study 2, the intervention was specifically aimed to create this link. Although results are consistent with this view (showing effects of reading fantasy on measures concerning the disadvantaged group), future studies should empirically assess how this transfer occurs. Relatedly, we cannot exclude that the observed effects may depend on other psychological mechanisms activated by reading. For instance, the effect may depend at least in part on mnemonic activation, such that reading activated similar narratives and related situations that in turn influenced our hypothesized mediator. Also, the intervention (Study 2) was not solely based on reading, rather it required a high degree of elaboration as a consequence of group discussions. Several processes were, therefore, in place, and factors that we did not measure in this study might have contributed to explaining the present results (e.g., empathy). Future research can, therefore, examine further related processes. Fourth, consistent with much collective action and contact research, we relied on a self-reported measure of intention to engage in collective action; generalization to actual behavior is, therefore, unknown. Fifth, we relied on a specific social context, whereas results may differ in post-conflictual societies or where conflict is severe, since resistance to acknowledge social inequalities and address them should be stronger.

In this research we presented two studies showing that reading The Hunger Games as a form of vicarious contact can help making the advantaged group members feel anger about unfair status relations and fostering their willingness to engage in collective action to promote social equality. We believe media vicarious contact via book reading is a powerful 
tool to reach a large number of individuals, and researchers should consider its potential to achieve social change in the wider society.

\section{CONFLICT OF INTEREST}

The authors declare no conflict of interest.

\section{DATA AVAILABILITY STATEMENT}

Data can be freely shared upon request to the first author of this article.

\section{ORCID}

Loris Vezzali https://orcid.org/0000-0001-7536-9994 Shelley

McKeown Jones https://orcid.

org/0000-0002-3837-3692

Gian Antonio Di Bernardo (iD) https://orcid.

org/0000-0002-3922-5712

\section{REFERENCES}

Adra, A., Harb, C., Li, M., \& Baumert, A. (2019). Predicting collective action tendencies among Filipina domestic workers in Lebanon:

Integrating the social identity model of collective action and the role of fear. Group Processes and Intergroup Relations, 23(7), 967-978.

https://doi.org/10.1177/13684 30219885180

Allport, G. W. (1954). The nature of prejudice. Addison-Wesley.

Andrews, N. P., Yogeeswaran, K., Walker, M. J., \& Hewstone, M. (2018). Effect of valenced vicarious online contact on out-group prejudice and perceived outgroup variability: A study of online poker.

Journal of Applied Social Psychology, 48(10), 571-581. https://doi. org/10.1111/jasp.12548

Asbrock, F., Christ, O., Duckitt, J., \& Sibley, C. G. (2012). Differential effects of intergroup contact for authoritarians and social dominators: A dual process model perspective. Personality \& Social Psychology

Bulletin, 38(4), 477-490. https://doi.org/10.1177/01461 67211429747

Asbrock, F., Gutenbrunner, L., \& Wagner, U. (2013). Unwilling, but not unaffected-Imagined contact effects for authoritarians and social dominators. European Journal of Social Psychology, 43(5), 404-412. https://doi.org/10.1002/ejsp.1956

Bandura, A. (1986). Social foundations of thought and action: A social cognitive theory. Prentice-Hall Inc.

Bandura, A. (2000). Exercise of human agency through collective efficacy. Current Directions in Psychological Science, 9(3), 75-78. https:// doi.org/10.1111/1467-8721.00064

Bandura, A. (2004). Social cognitive theory for personal and social change by enabling media. In A. Singhal, M. J. Cody, E. M. Rogers, \& M. Sabido (Eds.), Entertainment-education and social change: History, research, and practice (pp. 75-96). Lawrence Erlbaum.

Becker, J. C., \& Tausch, N. (2015). A dynamic model of engagement in normative and non-normative collective action: Psychological antecedents, consequences, and barriers. European Review of Social Psychology, 26(1), 43-92. https://doi.org/10.1080/10463 283.2015.1094265

Bem, D. J. (1972). Self-perception theory. In L. Berkowitz (Ed.), Advances in experimental social psychology (Vol. 6, pp. 1-99). Academic Press.

Bilali, R., \& Vollhardt, J. R. (2015). Do mass media interventions effectively promote peace in contexts of ongoing violence? Evidence from Eastern Democratic Republic of Congo. Peace and Conflict: Journal of Peace Psychology, 21(4), 604-620. https://doi.org/10.1037/pac00 00124

Bilali, R., Vollhardt, J. R., \& Rarick, J. R. D. (2016). Assessing the impact of a mediabased intervention to prevent intergroup violence and promote positive intergroup relations in Burundi. Journal of Community and Applied Social Psychology, 26(3), 221-235. https://doi. org/10.1002/casp.2246

Bilali, R., Vollhardt, J. R., \& Rarick, J. R. D. (2017). Modeling collective action through media to promote social change and positive intergroup relations in violent conflicts. Journal of Experimental Social Psychology, 68, 200-211. https://doi.org/10.1016/j.jesp.2016.07.005

Çakal, H., Hewstone, M., Schwär, G., \& Heath, A. (2011). An investigation of the social identity model of collective action and the "sedative" effect of intergroup contact among Black and White students in South Africa. British Journal of Social Psychology, 50(4), 606-627. https://doi. org/10.1111/j.2044-8309.2011.02075.x

Cameron, L., \& Rutland, A. (2006). Extended contact through story reading in school: Reducing children's prejudice toward the disabled. Journal of Social Issues, 62(3), 469-488. https://doi. org/10.1111/j.1540-4560.2006.00469.x

Castelli, L., Carraro, L., Pavan, G., Morelli, E., \& Carraro, A. (2012). The power of the unsaid: The influence of nonverbal cues on implicit attitudes. Journal of Applied Social Psychology, 42(6), 1376-1393. https:// doi.org/10.1111/j.1559-1816.2012.00903.x

Cooper, J., \& Hogg, M. A. (2007). Feeling the anguish of others: A theory of vicarious dissonance. Advances in Experimental Social Psychology, 39, 359403. https://doi.org/10.1016/S0065 -2601(06)39007-7

Crisp, R. J., \& Turner, R. N. (2012). The imagined contact hypothesis. Advances in Experimental Social Psychology, 46, 125-182. https://doi. org/10.1016/B978-0-12-39428 1-4.00003 -9

Crone, E. A., \& Dahl, R. E. (2012). Understanding adolescence as a period of social-affective engagement and goal flexibility. Nature Reviews Neuroscience, 13, 636-650. https://doi.org/10.1038/nrn3313

Dhont, K., \& Van Hiel, A. (2009). We must not be enemies: Interracial contact and the reduction of prejudice among authoritarians. Personality and Individual Differences, 46(2), 172-177. https://doi.org/10.1016/j. paid.2008.09.022

Di Bernardo, G. A., Vezzali, L., Stathi, S., McKeown, S., Cocco, V. M., Saguy, T., \& Dixon, J. (2019). Fostering social change among advantaged and disadvantaged group members: Integrating intergroup contact and social identity perspectives on collective action. Group Processes and Intergroup Relations. https://doi.org/10.1177/13684 30219889134

Dovidio, J. F. (2009). Racial bias, unspoken but heard. Science, 326(5960), 16411642. https://doi.org/10.1126/scien ce.1184231

Dovidio, J. F., Eller, A., \& Hewstone, M. (2011). Improving intergroup relations through direct, extended and other forms of in direct contact. Group Processes and Intergroup Relations, 14(2), 147-160. https://doi. org/10.1177/13684 30210390555

Ellemers, N., \& Barreto, M. (2009). Collective action in modern times: How modern expressions of prejudice prevent collective action. Journal of Social Issues, 65(4), 749-768. https://doi. org/10.1111/j.1540-4560.2009.01621.x

Gaertner, S. L., \& Dovidio, J. F. (2000). Reducing intergroup bias: The common ingroup identity model. Psychology Press.

Goldstein, N. J., \& Cialdini, R. B. (2007). The spyglass self: A model of vicarious self-perception. Journal of Personality and Social Psychology, 92(3), 402417. https://doi.org/10.1037/0022-3514.92.3.402

Górska, P., Stefaniak, A., Malinowska, K., Lipowska, K., Marchlewska, M., Budziszewska, M., \& Maciantowicz, O. (2020). Too great to act in solidarity: The negative relationship between collective narcissism and solidaritybased collective action. European Journal of Social Psychology, 50(3), 561578. https://doi.org/10.1002/ejsp.2638

Graf, S., \& Paolini, S. (2017). Investigating positive and negative intergroup contact. In L. Vezzali \& S. Stathi (Eds.), Intergroup contact theory: Recent developments and future directions (pp. 92-113). Routledge.

Green, M. C., \& Brock, T. C. (2000). The role of transportation in the persuasiveness of public narratives. Journal of Personality and Social Psychology, 79(5), 701-721. https://doi. org/10.1037/0022-3514.79.5.701

Green, M. C., \& Brock, T. C. (2002). In the mind's eye: Transportationimagery model of narrative persuasion. In M. C. Green, J. J. Strange, \& T. C. Brock (Eds.), Narrative impact: Social and cognitive foundations (pp. 315-341). Erlbaum. 
Hasan-Aslih, S., Pliskin, R., van Zomeren, M., Halperin, E., \& Saguy, T. (2019). A darker side of hope: Harmony-focused hope decreases collective action intentions among the disadvantaged. Personality and Social Psychology Bulletin, 45(2), 209-223. https://doi. org/10.1177/0146167218 783190

Hauser, T. U., lannaccone, R., Walitza, S., Brandeis, D., \& Brem, S. (2015). Cognitive flexibility in adolescence: Neural and behavioral mechanisms of reward prediction error processing in adaptive decision making during development. Neurolmage, 104, 347-354. https://doi. org/10.1016/j.neuro image.2014.09.018

Hayes, A. F. (2013). Introduction to mediation, moderation, and conditional process analysis: A regression-based approach. Guilford Press.

Hayward, L. E., Tropp, L. R., Hornsey, M. J., \& Barlow, F. K. (2018). How negative contact and positive contact with Whites predict collective action among racial and ethnic minorities. British Journal of Social Psychology, 57(1), 120. https://doi.org/10.1111/bjso.12220

Hodson, G., \& Dhont, K. (2015). The person-based nature of prejudice: Individual difference predictors of intergroup negativity. European Review of Social Psychology, 26(1), 1-42. https:// doi.org/10.1080/10463 283.2015.1070018

Hodson, G., Turner, R. N., \& Choma, B. L. (2017). Individual differences in intergroup contact propensity and prejudice reduction. In L. Vezzali \& S. Stathi (Eds.), Intergroup contact theory: Recent developments and future directions (pp. 8-30). Routledge.

Joyce, N., \& Harwood, J. (2014). Improving intergroup attitudes through televised vicarious intergroup contact: Social cognitive processing of ingroup and outgroup information. Communication Research, 41(5), 627643. https://doi.org/10.1177/00936 50212447944

Kauff, M., Schmid, K., Lolliot, S., Al Ramiah, A., \& Hewstone, M. (2016). Intergroup contact effects via ingroup distancing among majority and minority groups: Moderation by social dominance orientation. PLoS One, 11(1), e0146895. https://doi.org/10.1371/journ al.pone.0146895

Kaufman, G. F., \& Libby, L. K. (2012). Changing beliefs and behavior through experience-taking. Journal of Personality and Social Psychology, 103(1), 119. https://doi.org/10.1037/a0027525

Kidd, D. C., \& Castano, E. (2013). Reading literary fiction improves theory of mind. Science, 342(6156), 377-380. https://doi.org/10.1126/scien ce. 1239918

Krause, S., \& Appel, M. (2020). Stories and the self: Assimilation, contrast, and the role of being transported into the narrative world. Journal of Media Psychology: Theories, Methods, and Applications, 32(2), 47-58. https://doi.org/10.1027/1864-1105/a000255

Leach, C. W., Iyer, A., \& Pedersen, A. (2006). Anger and guilt about ingroup advantage explain the willingness for political action. Personality and Social Psychology Bulletin, 32(9), 1232-1245. https:// doi.org/10.1177/01461 67206289729

Lienemann, B. A., \& Stopp, H. T. (2013). The association between media exposure of interracial relationships and attitudes toward interracial relationships. Journal of Applied Social Psychology, 43(Suppl. 2), E398-E415. https://doi.org/10.1111/jasp.12037

Mäkinen, V., Liebkind, K., Jasinskaja-Lahti, I., \& Renvik, T. A. (2019). A teacherled vicarious contact intervention in culturally mixed classrooms with inand outgroup role models of intergroup friendship.

Journal of School Psychology, 75, 27-40. https://doi.org/10.1016/j. jsp.2019.07.002

Mar, R., \& Oatley, K. (2008). The function of fiction is the abstraction and simulation of social experience. Perspectives on Psychological Science, 3(3), 173-192. https://doi.org/10.1111/j.1745-6924.2008.00073.x

Mares, M. L., \& Pan, Z. (2013). Effects of Sesame Street: A meta-analysis of children's learning in 15 countries. Journal of Applied Developmental Psychology, 34(3), 140-151. https://doi.org/10.4135/97814 4627305015 595379

Mastro, D. (2009). Effects of racial and ethnic stereotyping. In J. Bryant \& M. B. Oliver (Eds.), Media effects: Advances in theory and research (3rd ed., pp. 325-341). Routledge.

Mazziotta, A., Mummendey, A., \& Wright, S. C. (2011). Vicarious intergroup contact effects: Applying social-cognitive theory to intergroup contact research. Group Processes and Intergroup Relations,
14(2), 255-274. https://doi.org/10.1177/1368430210390533

McKeown, S., \& Dixon, J. (2017). The "contact hypothesis": Critical reflections and future directions. Social and Personality Psychology Compass, 11(1), e12295. https://doi.org/10.1111/spc3.12295 McKeown, S., Williams, A., \& Pauker, K. (2017). Stories that move them: Changing children's behaviour toward diverse peers. Journal of Community and Applied Social Psychology, 27(5), 381-387. https://doi. org/10.1002/casp.2316

Meadows, A., Higgs, S., Burke, S. E., Dovidio, J. F., van Ryn, M., \& Phelan, S. M. (2017). Social dominance orientation, dispositional empathy, and need for cognitive closure moderate the impact of empathy-skills training, but not patient contact, on medical students' negative attitudes toward higherweight patients. Frontiers in Psychology, 8, 504.

https://doi.org/10.3389/fpsyg.2017.00504

Meleady, R., \& Vermue, M. (2019). The effect of intergroup contact on solidaritybased collective action is mediated by reductions in SDO.

Journal of Applied Social Psychology, 49(5), 307-318. https://doi. org/10.1111/jasp.12586

Miles, E., \& Crisp, R. J. (2014). A meta-analytic test of the imagined contact hypothesis. Group Processes and Intergroup Relations, 17(1), 3-26. https://doi.org/10.1177/13684 30213510573

Mutz, D. C., \& Goldman, S. K. (2010). Mass media. In J. F. Dovidio, M. Hewstone, P. Glick, \& V. M. Esses (Eds.), Handbook of prejudice, stereotyping, and discrimination (pp. 241-258). Sage.

Oatley, K. (2016). Fiction: Simulation of social worlds. Trends in Cognitive Science, 20(8), 618-628. https://doi.org/10.1016/j.tics.2016.06.002

Ortiz, M., \& Harwood, J. (2007). A social cognitive theory approach to the effects of mediated intergroup contact on intergroup attitudes.

Journal of Broadcasting and Electronic Media, 51, 615-631. https://doi. org/10.1080/08838 150701626487

Pennington, M. C., \& Waxler, R. P. (2017). Why reading books still matter: The power of literature in digital times. Routledge.

Pettigrew, T. F. (2009). Secondary transfer effect of contact: Do intergroup contact effects spread to noncontacted outgroups? Social Psychology, 40(2), 55-65. https://doi.org/10.1027/1864-9335.40.2.55

Pratto, F., Sidanius, J., \& Levin, S. (2006). Social dominance theory and the dynamics of intergroup relations: Taking stock and looking forward. European Review of Social Psychology, 17(1), 271-320. https:// doi.org/10.1080/10463280601055772

Pratto, F., Sidanius, J., Stallworth, L. M., \& Malle, B. F. (1994). Social dominance orientation: A personality variable predicting social and political attitudes. Journal of Personality and Social Psychology, 67(4), 741-763. https://doi.org/10.1037/0022-3514.67.4.741

Preuß, S., \& Steffens, M. C. (2020). A video intervention for every straight man: The role of preattitudes and emotions in vicarious-contact effects. Group Processes \& Intergroup Relations.

Reimer, N. K., Becker, J. C., Benz, A., Christ, O., Dhont, K., Klocke, U., Neji, S., Rychlowska, M., Schmid, K., \& Hewstone, M. (2017). Intergroup contact and social change: Implications of negative and positive contact for collective action in advantaged and disadvantaged groups.

Personality and Social Psychology Bulletin, 43(1), 121-136. https://doi. org/10.1177/01461 67216676478

Runciman, W. G. (1966). Relative deprivation and social justice: A study of attitudes to social inequality in twentieth-century England. University of California Press.

Saab, R., Tausch, N., Spears, R., \& Cheung, W.-Y. (2015). Acting in solidarity: Testing an extended dual pathway model of collective action by bystander group members. British Journal of Social Psychology, 54(3), 539-560. https://doi.org/10.1111/bjso.12095

Saguy, T., Shchory-Eyal, N., Hasan-Aslih, S., Sobol, D., \& Dovidio, J. F. (2017). The irony of harmony: Past and new developments. In L. Vezzali \& S. Stathi (Eds.), Intergroup contact theory: Recent developments and future directions (pp. 53-71). Routledge.

Schiappa, E., Gregg, P. B., \& Hewes, D. E. (2005). The parasocial contact hypothesis. Communication Monographs, 72(1), 92-115. https://doi. org/10.1080/03637 75052000342544 
Schmid, K., Hewstone, M., Küpper, B., Zick, A., \& Wagner, U. (2012). Secondary transfer effects of intergroup contact: A cross-national comparison in Europe. Social Psychology Quarterly, 75(1), 28-51.

https://doi.org/10.1177/01902 72511430235

Selvanathan, H. P., Techakesari, P., Tropp, L. R., \& Barlow, F. K. (2017). Whites for racial justice: How contact with Black Americans predicts support for collective action among White Americans. Group Processes and Intergroup Relations, 21(6), 893-912. https://doi. org/10.1177/1368430217690908

Shaffer, V. A., Focella, E. S., Hathaway, A., Scherer, L. D., \& ZikmundFisher, B. J. (2018). On the usefulness of narratives: An interdisciplinary review and theoretical model. Annals of Behavioral Medicine, 52(5), 429-442. https://doi.org/10.1093/abm/kax008

Sidanius, J., \& Pratto, F. (1999). Social dominance: An intergroup theory of social hierarchy and oppression. Cambridge University Press.

Simon, B., \& Klandermans, B. (2001). Politicized collective identity: A social psychological analysis. American Psychologist, 56(4), 319-331. https://doi.org/10.1037/0003-066X.56.4.319

Smith, H. J., Pettigrew, T. F., Pippin, G. M., \& Bialosiewicz, S. (2012). Relative deprivation: A theoretical and meta-analytical review.

Personality and Social Psychology Review, 16(3), 203-232. https://doi. org/10.1177/10888 68311430825

Stathi, S., Crisp, R. J., Turner, R. N., West, K., \& Birtel, M. (2012). Using mental imagery to promote positive intergroup relations. In D. W. Russel \& C. A. Russel (Eds.), The psychology of prejudice: Interdisciplinary perspectives on contemporary issues (pp. 235-250). Nova publishers.

Stathi, S., Vezzali, L., Waldzus, S., \& Hantzi, A. (2019). The mobilizing and protective role of national identification in normative and non-normative collective action. Journal of Applied Social Psychology, 49(9), 596-608. https://doi.org/10.1111/jasp.12619

Steinberg, L. (2005). Cognitive and affective development in adolescence. Trends in Cognitive Sciences, 9(2), 69-74. https://doi.org/10.1016/j. tics.2004.12.005

Stürmer, S., \& Simon, B. (2004). The role of collective identification in socia movement participation: A panel study in the context of the German gay movement. Personality and Social Psychology Bulletin, 30(3), 263-277. https://doi.org/10.1177/0146167203 256690

Subašić, E., Reynolds, K. J., \& Turner, J. C. (2008). The political solidarity model of social change: Dynamics of self-categorization in intergroup power relations. Personality and Social Psychology Review, 12(4), 330- 352. https://doi.org/10.1177/10888 68308323223

Tajfel, H., \& Turner, J. C. (1979). An integrative theory of intergroup conflicts. In W. G. Austin \& S. Worchel (Eds.), The social psychology of intergroup relations (pp. 33-47). Brooks-Cole.

Tausch, N., Saguy, T., \& Bryson, J. (2015). How does intergroup contact affect social change? Its impact on collective action and individual mobility intentions among members of a disadvantaged group. Journal of Social Issues, 71(3), 536-553. https://doi.org/10.1111/ josi.12127

Thomas, E. F., Mavor, K. I., \& McGarty, C. (2012). Social identities facilitate and encapsulate action-relevant constructs: A test of the social identity model of collective action. Group Processes and Intergroup Relations, 15(1), 75-88. https://doi.org/10.1177/1368430211 413619

Thomas, E. F., McGarty, C., \& Mavor, K. I. (2009). Transforming "apathy into movement": The role of prosocial emotions in motivating action for social change. Personality and Social Psychology Review, 13(4), 310-333. https://doi.org/10.1177/10888 68309343290

Thomas, E. F., Zubielevitch, E., Sibley, C. G., \& Osborne, D. (2020). Testing the social identity model of collective action longitudinally and across structurally disadvantaged and advantaged groups.

Personality and Social Psychology Bulletin, 46(6), 823-838. https://doi. org/10.1177/0146167219879111

Ufkes, E. G., Dovidio, J. F., \& Tel, G. (2015). Identity and collective action among European Kurds. British Journal of Social Psychology, 54(1),

176-186. https://doi.org/10.1111/bjso.12084 van Zomeren, M., Leach, C. W., \& Spears, R. (2012). Protesters as "passionate economists": A dynamic dual pathway model of approach coping with collective disadvantage. Personality and Social Psychology Review, 16(2), 180-199. https://doi.org/10.1177/10888 68311
430835 van Zomeren, M., Postmes, T., \& Spears, R. (2008). Toward an integrative social identity model of collective action: A quantitative research synthesis of three socio-psychological perspectives. Psychological Bulletin, 134(4), 504-535. https://doi.

org/10.1037/0033-2909.134.4.504

van Zomeren, M., Spears, R., Fischer, A. H., \& Leach, C. W. (2004). Put your money where your mouth is! Explaining collective action tendencies through group-based anger and group efficacy. Journal of Personality and Social Psychology, 87(5), 649-664. https://doi. org/10.1037/00223514.87.5.649

Verkuyten, M., Thijs, J., \& Bekhuis, H. (2010). Intergroup contact and ingroup reappraisal: Examining the deprovincialization thesis. Social Psychology Quarterly, 73(4), 398-416. https://doi.org/10.1177/01902 72510389015

Vezzali, L., Andrighetto, L., Capozza, D., Di Bernardo, G. A., \& Saguy, T. (2017) Discussing differences between groups: The content of intergroup encounters and motivation for social change among members of advantaged groups. Journal of Theoretical Social Psychology, 1(2), 52-59. https://doi.org/10.1002/jts5.12

Vezzali, L., Di Bernardo, G. A., Stathi, S., Visintin, E. P., \& Hewstone, M. (2019). Using intercultural videos of direct contact to implement vicarious contact: $A$ school-based intervention that improves intergroup attitudes. Group Processes and Intergroup Relations, 22(7), 1059-1076. https://doi.org/10.1177/13684 30218809885 Vezzali, L., Hewstone, M., Capozza, D., Giovannini, D., \& Wölfer, R. (2014). Improving intergroup relations with extended and vicarious forms of indirect contact. European Review of Social Psychology, 25(1), 314-389. https://doi.org/10.1080/10463 283.2014.982948

Vezzali, L., \& Stathi, S. (2021). Using intergroup contact to fight prejudice and negative attitudes: Psychological perspectives. In European Monographs in Social Psychology Series. Routledge.

Vezzali, L., Stathi, S., \& Giovannini, D. (2012). Indirect contact through book reading: Improving adolescents' attitudes and behavioral intentions toward immigrants. Psychology in the Schools, 49(2), 148-162. https://doi.org/10.1002/pits.20621

Vezzali, L., Stathi, S., Giovannini, D., Capozza, D., \& Trifiletti, E. (2015). The greatest magic of Harry Potter: Reducing prejudice. Journal of Applied Social Psychology, 45(2), 105-121. https://doi.org/10.1111/ jasp.12279

Visintin, E. P., Berent, J., Green, E. G. T., \& Falomir-Pichastor, J. M. (2019). The interplay between social dominance orientation and intergroup contact in explaining support for multiculturalism. Journal of Applied Social Psychology, 49(5), 319-327. https://doi.org/10.1111/ jasp.12587

Visintin, E. P., Voci, A., Pagotto, L., \& Hewstone, M. (2017). Direct, extended, and mass-mediated contact with immigrants in Italy: Their associations with emotions, prejudice, and humanity perceptions.

Journal of Applied Social Psychology, 47(4), 175-194. https://doi. org/10.1111/jasp.12423

Wang, C., Huang, F., Stathi, S., \& Vezzali, L. (2020). Positive and negative intergroup contact and willingness to engage in intergroup interactions among majority and minority group members: The moderating role of social dominance orientation. International Journal of Intercultural Relations, 75(1), 132-140. https://doi.org/10.1016/j.ijint rel.2018.09.002

Weisbuch, M., Pauker, K., \& Ambady, N. (2009). The subtle transmission of race bias via televised nonverbal behavior. Science, 326(5960), 1711-1714. https://doi.org/10.1126/scien ce.1178358

West, K., \& Turner, R. N. (2014). Using extended contact to improve physiological responses and behaviour toward people with schizophrenia. Journal of Experimental Social Psychology, 50(1), 57-64. https://doi. org/10.1016/j.jesp.2013.06.009

Wojcieszak, M., \& Azrout, R. (2016). I saw you in the news: Mediated and direct intergroup contact improve outgroup attitudes. Journal of Communication, 66(6), 1032-1060. https://doi.org/10.1111/ jcom.12266

Wright, S. C., Aron, A., McLaughlin-Volpe, T., \& Ropp, S. A. (1997). The extended contact effect: Knowledge of cross-group friendships and prejudice. Journal of Personality and Social Psychology, 73(1), 73-90. https://doi.org/10.1037/0022-3514.73.1.73 
Wright, S. C., \& Lubensky, M. E. (2009). The struggle for social equality: Collective action versus prejudice reduction. In S. Demoulin, J. P.

Leyens, \& J. F. Dovidio (Eds.), Intergroup misunderstandings: Impact of divergent social realities (pp. 291-310). Psychology Press.

Zhou, S., Page-Gould, E., Aron, A., Moyer, A., \& Hewstone, M. (2019). The extended contact hypothesis: A meta-analysis on 20 years of research. Personality and Social Psychology Review, 23(2), 132-160. https://doi.org/10.1177/10888 68318762647

\section{SUPPORTING INFORMATION}

Additional supporting information may be found online in the Supporting Information section.

How to cite this article: Vezzali L, McKeown S, MacCauley P, et al. May the odds be ever in your favor: The Hunger Games and the fight for a more equal society. (Negative) Media vicarious contact and collective action. J Appl Soc Psychol. 2021;51:121-137. https://doi.org/10.1111/jasp.12721 